\title{
Theorie und Wirklichkeit der Integrationsverantwortung deutscher Verfassungsorgane
}

\author{
Vom Scheitern eines verfassungsgerichtlichen Konzepts und seiner Überwindung
}

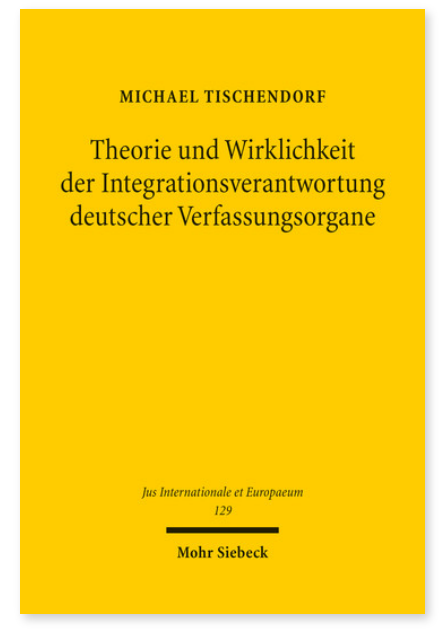

2017. XXII, 349 Seiten. JusIntEu 129

ISBN 978-3-16-155270-0

DOI 10.1628/978-3-16-155270-0

eBook PDF $94,00 €$

ISBN 978-3-16-155269-4

fadengeheftete Broschur $94,00 €$
Mit dem Konzept der Integrationsverantwortung hat das Bundesverfassungsgericht ein für das Verhältnis von nationalem Verfassungs- und europäischem Unionsrecht zentrales Rechtsinstitut geschaffen, das insbesondere dem deutschen Bundesgesetzgeber aufgibt, den Prozess der europäischen Integration aktiv zu steuern und zu überwachen. Hintergrund ist dabei die Annahme, dass allein die in den Mitgliedstaaten verfassten Staatsvölker Subjekte demokratischer Legitimation sein könnten. Die Europäische Union bilde demgegenüber lediglich einen abgeleiteten politischen Sekundärraum, dessen Befugnisse eng umgrenzt bleiben müssten. Michael Tischendorf beleuchtet Ursprünge, Grundlagen und Ausformungen dieses im Jahre 2009 interpretativ gewonnenen Konzepts, um es sodann mit seiner rechtstatsächlichen Handhabung zu konfrontieren. Dabei lenkt er den Blick auf zahlreiche Schwierigkeiten, deren Überwindung die Frage nach der Verfasstheit Deutschlands neu entfachen könnte.

Michael Tischendorf Geboren 1989; Studium der Rechtswissenschaften in Augsburg und Lyon (2012 Maîtrise en droit, 2014 Erste Juristische Prüfung); 2016 Promotion; seit 2016 Rechtsreferendariat im OLG-Bezirk München.
Jetzt bestellen:
https://mohrsiebeck.com/buch/theorie-und-wirklichkeit-der-integrationsverantwortung-deutscher-verfassungsorgane-
9783161552700 ?no_cache=1
order@mohrsiebeck.com
Telefon: +49 (0)7071-923-17
Telefax: +49(0)7071-51104 